\title{
Study on a Caisson Based OWC Wave Energy Converting System
}

\author{
Y.-F. Chiu ${ }^{1}$, Hsien Hua Lee ${ }^{2, a}$, C.-Y. Lin², and C.-H. Chen ${ }^{2}$ \\ ${ }^{1}$ Harbor and Marine Technology Center, IOT of MOCT, Taichung, Taiwan \\ ${ }^{2}$ Department of Marine Environment and Engineering, National Sun Yat-sen University, Kaohsiung, \\ Taiwan \\ a email: hhlee@mail.nsysu.edu.tw
}

\begin{abstract}
Keywords: Breakwater Design, Wave Energy, Wave Power Converting System, Caisson Breakwater Application
\end{abstract}

\begin{abstract}
This study proposes an alternative way, so called caisson based OWC type wave energy converting system to collect and convert wave energy into electricity. A numerical method by using a theorem of unsteady Navier-Stokes Equations in conservation form is used to analyze the proposed structural model. The analysis focuses on the interactions between the wave motion and the air pressure, and the variations of the air flow in the chamber when the structure subjected to an incident wave. The limited analytical results appear to be very encouraging for the proposed caisson modified structure as an alternative for green energy developments. It is found that the analytical results are compared well with the findings of Goda et al. and the dimensional parameters of the converter are closely related to environmental factors.
\end{abstract}

\section{Introduction}

Intensive studies for a wave-power converting system were performed during late 1980s and then 1990s, but however, a combination with breakwater system was firstly studied in Japan [5, 6]. In those advanced studies, not only experimental tests were performed but also on-site full-scale structure was built and tested. Many valuable data were acquired and some important results were concluded. Important conclusions including: the efficiency of power can be obtained from the conversion system, the estimated direct cost for a system of comparable size and scale, a range of dimensional ratio between the air chamber and the wavelength and the most important one that the combination for a breakwater with the wave-power converting system would not affect the function of the breakwater but reinforce it.

Unfortunately, even though the study from Goda et al. [5, 6] is invaluable and pioneering, it is too hard and too costly to be repeated for an on-field experiment. It is also too much confined by many local factors for a special case to apply to the caisson breakwater in other different locations. However, by following the findings of Goda et al. and the contemporary studies [1-4, 7], a series of studies are being performed by adopting but upgrading a similar system, so called the caisson based OWC type wave energy converter for green energy developments. It is focusing on the analysis of the interactions between the wave motion and the air pressure, the variations of the air flow and pressure, the deformations of the structural members (curtain wall) of breakwater subjected to an incident wave and also the variations of pressures inside the air-chamber, the motions of the whole breakwater and the efficiency of the converting system when some of the parameters of the system are varied. This study as a very first part of the serial studies, uses a numerical method to analyze the proposed model structure. The limited results are found compared well with findings of Goda et al. and very encouraging for the proposed method as an alternative for green energy developments.

\section{Theorem Applied in the Study}

In this study a theorem of unsteady Navier-Stokes Equations in conservation form consisting of 
continuity equations, equation of momentums and equation of turbulence dynamics are applied and shown as follows.

Continuity equation:

$$
\frac{\partial \rho}{\partial t}+\nabla \cdot(\rho U)=0
$$

equation of momentum

$$
\frac{\partial \rho U}{\partial t}+\nabla \cdot(\rho U \times U)-\nabla \cdot\left(\mu_{e f f} \nabla U\right)=\nabla \cdot p^{I}+\nabla \cdot\left(\mu_{e f f} \nabla U\right)^{T}+B
$$

equation of turbulence dynamic energy

$$
\frac{\partial(\rho k)}{\partial t}+\nabla \cdot(\rho U k)=\nabla \cdot\left[\left(\mu+\frac{\mu_{t}}{\sigma_{k}}\right) \nabla k\right]+P_{k}-\rho \varepsilon
$$

Since these equations are well known for fluid dynamics, descriptions of parameters in equations are omitted.

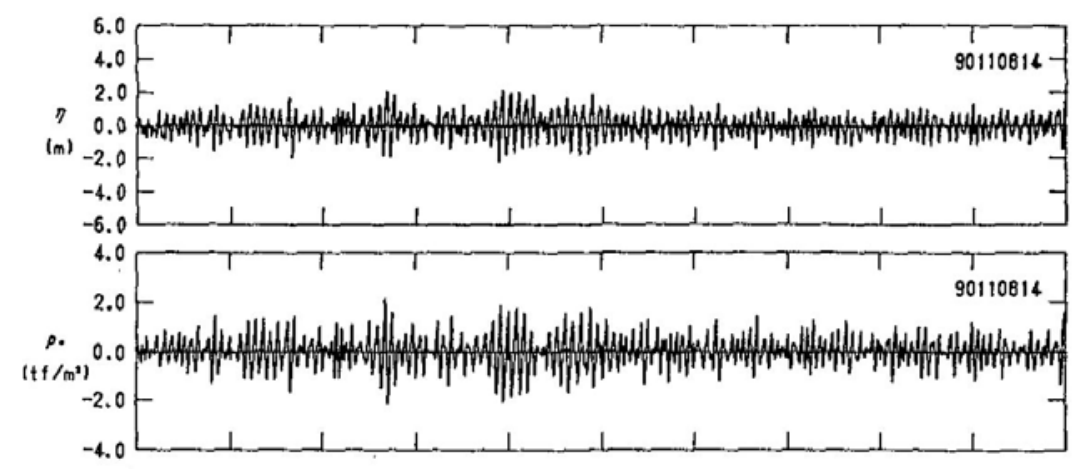

Fig.1 The testing results of wave power extracting caisson breakwater (reproduced from Goda [5])

\section{Verification of the Numerical Study}

In order to verify if the applied theorem of fluid dynamics and the numerical tool is suitable to simulate a caisson based OWC system of large scale, an effort was put to reproduce the results from the on-field study of Goda's experiment in Sakeda, a study that is currently the sole one may provide the on-field experimental data for a full-scale running wave energy converter. Shown in Fig.1 is the testing data from a full-scale model for a caisson breakwater installed with a wave power extracting system. The experimental data available from this study is limited and shown in curves including both the pressure variation and the water level variation in the chamber. Therefore, the comparison between analytical study and experimental data will be confined into pressures and elevations of the water bodies in the chamber.

As shown in Fig.2 are comparisons for the variations of both water elevation and pressures in the chamber. It is noticed from the comparison that the analytical results for the average water elevation in the chamber are conservative compared to the experimental data but for the extreme values both in the high and low elevations, the analytical results are in very good match with experimental data. As for the pressure, the average are also more conservative while the maximum value of pressure is smaller but for the minimum pressure, the analytical results is close to the experimental one. The conservative results in the average water elevation also explains a conservative trend of average pressure in analysis. 


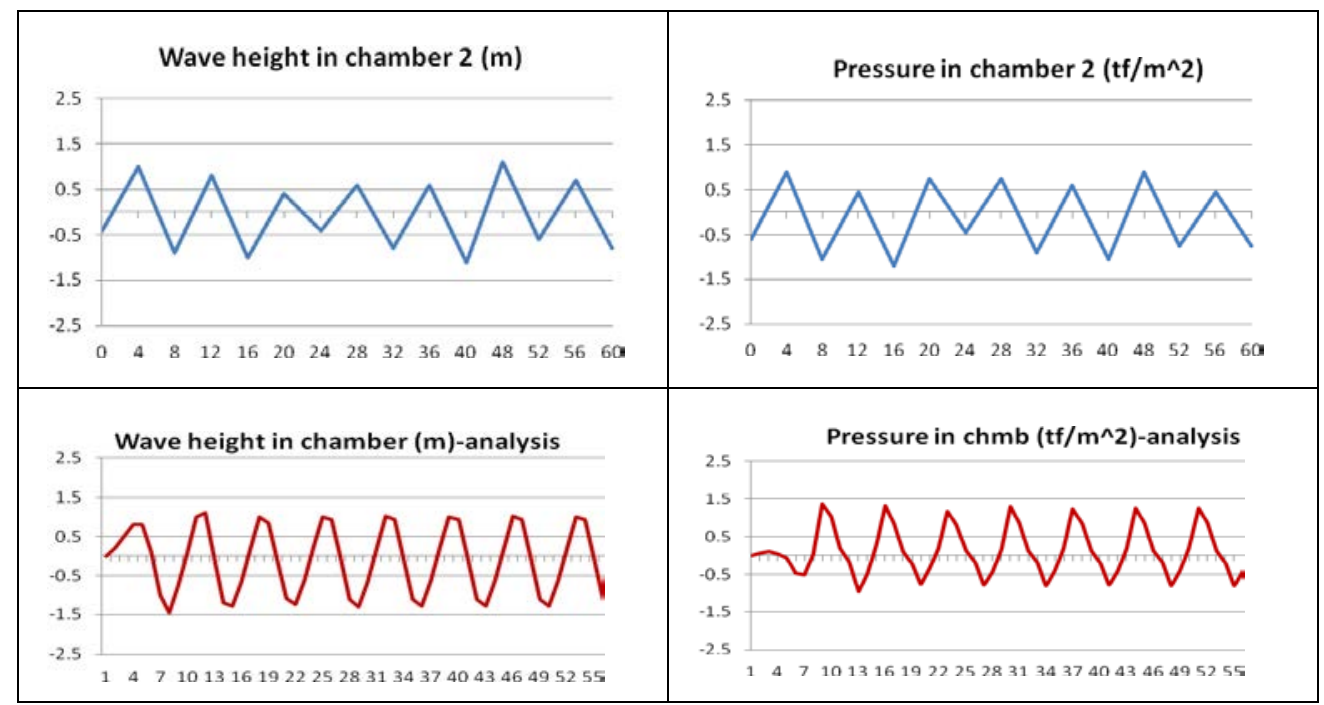

Fig.2 Comparison for the variations of both pressures and water elevation

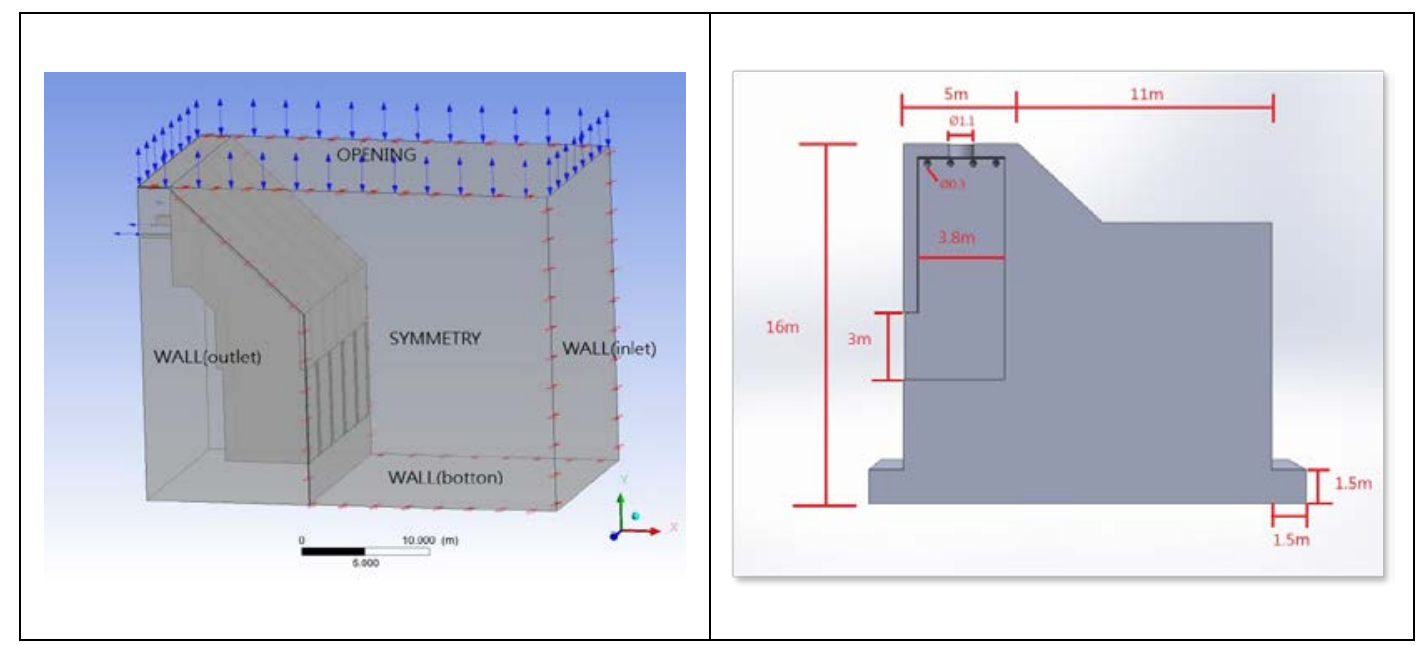

Fig.3 Analytical model for the proposed OWC type caisson based wave energy converter

\section{Results of Case Analysis and Discussion}

For the proposed caisson based OWC type wave energy converting system, not only are the dimensions and designs essential but the local environmental parameters are critical since they are different from the case that is verified for the analytical method. However, with the good agreement from the verification of the analytical method, it is confident that the analytical results for the proposed caisson based wave converting system are reliable for the design procedure.

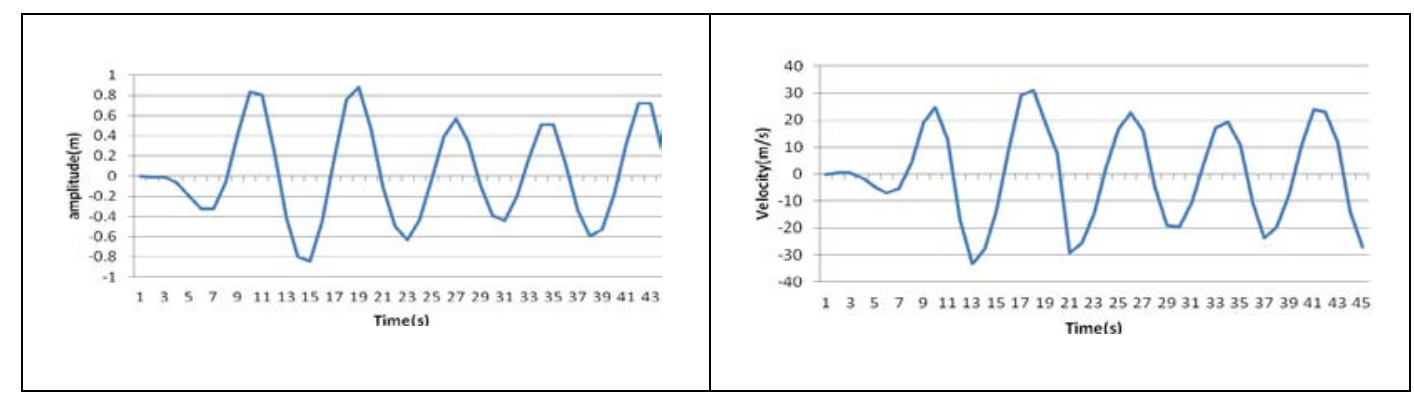

Fig.4 Variations for the water elevation and air speed in the opening nuzzle

The proposed caisson based OWC type wave energy converting system is shown in Fig.3, where 
the right one simulates a section of the proposed design in a 3-D model along with water body while the other shows the cross-section of the proposed structure. The water-body with open surface-field that incidents waves travelling toward the structure is also implemented and symmetrical boundaries on the side is assumed. The dimensions of the OWC chamber is also shown, where the opening for incident waves is $3 \times 3 \mathrm{~m}$ and there is a small opening for air-flow to drive the turbine system on the top lid of each chamber, which is connected each other with several orifices near the top between the segregation walls. On the back of the OWC chambers a supporting caisson breakwater is appropriately designed following related construction code.

In the analysis, a wave of one meter height and 7 seconds of period is applied. The parameters are from the observation records and selected as the waves that may occur routinely. The analytical results are shown in Fig.4 for the variation of water elevation in the chamber and the speed of air-flow through the nuzzle, an opening located at the top lid of the chamber. It is noticed that the water elevation in the chamber could reach as high as one meter that is very similar to the on-field study of Goda. The air-speed on the top opening can reach as high as $30 \mathrm{~m} / \mathrm{second}$ that is a cut-out wind speed for a small wind power electricity generator. Therefore, for appropriate design of an electricity generator, this caisson based OWC type wave energy converter can be very attractive as a good alternative of green energy development.

\section{Conclusions}

This study proposes an alternative way, so called caisson based OWC type wave energy converter for green energy developments. The method used to analyze the proposed model is verified to be accurate enough for a similar structure. The limited analytical results appears to be very encouraging for the proposed method as an alternative for green energy developments.

\section{Acknowledgements}

This study has been financially supported by Harbor and Marine Technology Center, IOT of MOCT, Taiwan. It is gratefully acknowledged here.

\section{References}

[1] Boccotti, P. (2005) Comparison between a U-OWC and a conventional OWC, Ocean Engineering, Vol. 34,pp 799-805.

[2] Boccotti, P. (2006) Caisson breakwaters embodying an OWC with a small opening. Part I: theory. Ocean Engineering, in press, doi:10.1016/j.oceaneng.2006.04.006.

[3] Boccotti, P. (2006) Caisson breakwaters embodying an OWC with a small opening. Part II: a small scale field experiment. Ocean Engineering, in press, doi:10.1016/j.oceaneng.2006.04.016.

[4] Dorrell, D.G. and M. F. Hsieh (2008) Performance of Wells Turbines for Use in Small-Scale Oscillating Water Columns, International Society of Offshore and Polar Engineering Conference, ISOPE 2008, Vancouver, July 2008.

[5] Goda, Y., H. Nakada, H. Ohneda, M. Suzuki, S. Takahashi and M. Shikamori (1991) Results of field experiment of a wave power extracting caisson breakwater, Proceedings of Ocean Developments, Japan, Vol. 7, pp. 143-148.

[6] Goda, Y., T. Shinda, S. Chiyama, H. Ohneda, M. Suzuki, S. Takahashi, M. Shikamori and Y. Takaki (1989) Experiment of a wave power extracting caisson breakwater, Proceedings of Ocean Developments, Japan, Vol. 5, pp. 1-6.

[7] Lee, H. H. and Jeng, Min-Liang (2014) Experimental Study on the Floating Type of Wave Power Converter with Guide-Piles, Ocean Engineering -An Int. Journal (In press). 